\title{
Acute Respiratory Distress Syndrome from Tick-borne Human Granulocytic Anaplasmosis Infection
}

\author{
Vedang Patel, MD \\ Thomas Jefferson University, vedang.patel@jefferson.edu
}

Follow this and additional works at: https://jdc.jefferson.edu/tmf

Part of the Medicine and Health Sciences Commons

\section{Let us know how access to this document benefits you}

\section{Recommended Citation}

Patel, MD, Vedang (2015) "Acute Respiratory Distress Syndrome from Tick-borne Human Granulocytic Anaplasmosis Infection," The Medicine Forum: Vol. 16, Article 6.

DOI: https://doi.org/10.29046/TMF.016.1.005

Available at: https://jdc.jefferson.edu/tmf/vol16/iss1/6

This Article is brought to you for free and open access by the Jefferson Digital Commons. The Jefferson Digital Commons is a service of Thomas Jefferson University's Center for Teaching and Learning (CTL). The Commons is a showcase for Jefferson books and journals, peer-reviewed scholarly publications, unique historical collections from the University archives, and teaching tools. The Jefferson Digital Commons allows researchers and interested readers anywhere in the world to learn about and keep up to date with Jefferson scholarship. This article has been accepted for inclusion in The Medicine Forum by an authorized administrator of the Jefferson Digital Commons. For more information, please contact: JeffersonDigitalCommons@jefferson.edu. 


\title{
Acute Respiratory Distress Syndrome from Tick-borne Human Granulocytic Anaplasmosis Infection
}

\author{
Vedang Patel, MD
}

\section{INTRODUCTION}

Tick-borne infections were first formally recognized over a century ago, but it was only in 1990 that the first case of human granulocytic anaplasmosis (HGA), a tick-borne infection caused by Anaplasma phagocytophilum, was identified. ${ }^{12}$ Like other tick-borne infections, HGA presents as a nonspecific febrile illness. The most common clinical features are fever, headache, myalgia and malaise. ${ }^{2}$ This case report presents a rare but serious complication of HGA - acute respiratory distress syndrome (ARDS).

\section{CASE PRESENTATION}

A 49-year-old female with no past medical history presented to her local emergency department with complaints of fevers, headache, neck pain, myalgia, and malaise. She denied symptoms of upper respiratory tract infection, diarrhea, dysuria, rashes, and bleeding or bruising. She worked as an administrative assistant and lived on a farm in a rural area of Pennsylvania. She was in a monogamous relationship. She drank alcohol socially, and she was not known to use any illicit drugs

Her vital signs were temperature of 102 degrees Fahrenheit, pulse of 100 beats per minute, oxygen saturation of $98 \%$ on room air, and respiratory rate of 18 breaths per minute. On physical examination, she appeared fatigued but was alert and oriented to person, place, and time. There were no focal neurologic deficits. Her oropharynx was clear. Her neck was supple with full range of motion. Brudzinski and Kernig test were negative. Her lungs were clear to auscultation. Cardiac exam revealed tachycardia but no murmurs, rubs, or gallops. Her abdomen was soft and non-tender. There were no stigmata of liver disease. She had no rashes and no cutaneous bleeding. There were no palpable lymph nodes

Laboratory evaluation revealed a white blood cell count of $2 \times 10^{\%} / \mathrm{L}$ (normal range $=4-11 \times 10^{\circ} / \mathrm{L}$ ), platelet count of 43 $\times 10^{\circ} / \mathrm{L}$ (normal range $=140-400 \times 10^{\%} / \mathrm{L}$ ), and hemoglobin of $11 \mathrm{~g} / \mathrm{dL}$ (normal range $=14-17 \mathrm{~g} / \mathrm{dL}$ ). Her liver function panel revealed an aspartate aminotransferase (AST) of 923 $\mathrm{U} / \mathrm{L}$ (normal range $=7-42 \mathrm{U} / \mathrm{L}$ ) and alanine aminotrans- ferase $(A L T)$ of $946 \mathrm{U} / \mathrm{L}$ (normal range $=1-45 \mathrm{U} / \mathrm{L}$ ). Her bilirubin and alkaline phosphatase were mildly elevated. The patient was admitted for Systemic Inflammatory Response Syndrome (SIRS). She was empirically started on vancomycin and piperacillin-tazobactam. On her first day of admission she developed hypoxemic respiratory failure. A chest x-ray showed bilateral airspace opacities without evidence of volume overload. Mechanical ventilation was initiated and doxycycline was added. She was transferred to Thomas Jefferson University Hospital for management of ARDS.

\section{DIFFERENTIAL DIAGNOSIS}

The patient's high fevers and acute onset of symptoms suggested an infectious etiology. Cerebrospinal fluid testing was negative for viral, fungal, and bacterial pathogens. Bronchoalveolar lavage was lymphocytepredominant, and testing for viral, fungal, and bacterial respiratory pathogens was also negative. A right upper quadrant abdominal ultrasound was unremarkable. Given that she lived on a farm with deer nearby and the laboratory findings of leukopenia, thrombocytopenia, and elevated liver enzymes, there was concern for a tick-borne infection. Blood tests for Lyme, Ehrlichia, Babesia, and Rocky Mountain Spotted Fever (RMSF) were negative. Serum IgM and IgG for Anaplasma were negative, but Anaplasma DNA testing via real time polymerase chain reaction (PCR) was positive.

\section{OUTCOME AND FOLLOW-UP}

The patient was ventilated per the ARDS protocol, with a tidal volume of $6 \mathrm{~mL} / \mathrm{kg}$. Once the diagnosis of HGA was confirmed, vancomycin and piperacillin-tazobactam were discontinued and doxycycline, the treatment of choice for Anaplasma, was continued. After three days in the medical intensive care unit the patient was successfully extubated. At the time of discharge her blood cell counts had normalized and her liver enzymes were improving. Her chest x-ray demonstrated resolution of the bilateral airspace opacities. The patient was discharged home to complete a 14-day course of oral doxycycline. 


\section{DISCUSSION}

HGA is characterized by a febrile illness that most often presents with headache, myalgia, and fatigue. The first case of HGA in a human was in 1990 when a Wisconsin man died two weeks after being bitten by a tick. In the United States, the Centers for Disease Control and Prevention has recorded 2135 cases between 1994 and 2002, the last year for complete data.2.3 The incidence of HGA is rising and cases are often unreported. ARDS, the most serious complication seen in this patient's clinical course, has been reported in less than $1 \%$ of cases of HGA.

ARDS is characterized by hypoxemic respiratory failure, radiographic evidence of bilateral airspace opacities without volume overload, and an arterial oxygen pressure $(\mathrm{PaO} 2)$ to inspired oxygen fraction (FiO2) ratio of less than $300 \mathrm{mmHg}$. Sepsis, aspiration, pneumonia, and trauma are the most common causes of ARDS. 5.6 Patients require high levels of oxygen supplementation during the first several days, and clinical improvement usually depends on treatment of the underlying cause. Unlike traditional mechanical ventilation strategies that use 10 to $15 \mathrm{~mL} / \mathrm{kg}$ of tidal volume, a low tidal volume approach of 6 to $8 \mathrm{~mL} / \mathrm{kg}$ has been shown to decrease mortality and improve clinical outcomes in patients with ARDS. ${ }^{6}$ The consequences of ARDS include impaired gas exchange, decreased lung compliance, and pulmonary hypertension. Thus, it is imperative to make a diagnosis of the underlying cause and to begin immediate treatment.

The diagnosis of HGA is often difficult because symptoms develop days after the tick bite but seroconversion takes 2 to 4 weeks. If testing for antibodies is being considered, 2 serum samples should be taken at least 2 to 3 weeks apart and a 4-fold rise in antibody titer is needed to make the diagnosis. A Wright- or Giemsa-stained peripheral blood smear may provide early diagnosis by detecting morulae in neutrophils. ${ }^{2}$ Confirmation of HGA now often relies on PCR testing. but PCR is not readily available at all facilities. Therefore diagnosis often relies on clinical signs and symptoms, and treatment should not be delayed for confirmation of diagnosis. HGA infection is most common in the spring and summer months. The vector for transmission is the deer tick Ixodes scapularis. ${ }^{1}$ The highest incidence in the United States is in the northeast and north central states. Laboratory findings suggestive of HGA are leukopenia (present in $50 \%$ of cases), thrombocytopenia (94\%), and transaminitis $(90 \%)$. $^{2}$ This patient had all of the common laboratory features, presented in late spring, and lived in the northeast United States.

The treatment of choice for adults with HGA is doxycycline at a dose of $100 \mathrm{mg}$ orally every 12 hours for 7 to 14 days. In patients who are pregnant or have a tetracycline allergy, rifampin at $300 \mathrm{mg}$ twice daily may be substituted. 2,8 Symptoms start to resolve within 24 to 48 hours, and in patients who do not show clinical improvement a co-existing Babesia infection should be considered. ${ }^{2}$ Treatment with doxycycline and a low tidal volume mechanical ventilation strategy were pivotal to this patient's favorable outcome.

\section{KEY POINTS}

Headache, myalgia, and fatigue are the most common symptoms of HGA. Seroconversion takes two weeks so PCR testing is the test of choice for diagnosis. If suspicion for HGA is high, treatment with doxycycline should not be delayed for confirmation of diagnosis. ARDS is a very rare complication of HGA. Treatment with doxycycline and a low-tidal volume mechanical ventilation strategy were essential for the favorable outcome in this patient.

\section{REFERENCES}

1. Bakken JS, Dumler S. Huamn Granulocytic Anaplasmosis. Infectious Disease Clinics of North America. 2008; Volume 22: 433-448.

2. St Clair K, Decker CF. Ehrlichioses: Anaplasmosis and Human Ehrlichosis. Diseases a Month. 2012. 346-354

3. Dumler JS, Choi KS, Garcia-Garcia JC, Barat NS, Scorpio DG, Garyu JW, Grab DJ, Bakken JS. Human Granulocytic Anaplasmosis and Anaplasma phagocytophilum. Emerging Infectious Diseases. Dec 2005; 11(12): 1828-1834.

4. Dumler JS, Madigan JE, Pusteria N, Bakken JS. Ehrlichioses in Humans: Epidemiology, Clinical Presentation, Diagnosis, and Treatment. Clinical Infectious Disease. 2007; Volume 45 Supplement 1: S45-S51.

5. Silversides JA, Ferguson ND. Clinical Review: Acute Respiratory Distress Syndrome - Clinical Ventilator Management and Adjunct Therapy. Critical Care. 2013; Volume 17(2): 225-234.

6. The Acute Respiratory Distress Syndrome Network. Ventilation with Lower Tidal Volumes as Compared with Traditional Tidal Volumes for Acute Lung Injury and the Acute Respiratory Distress Syndrome. May 2000; Volume 342 Number 18: 1301-1308.

7. Melot C, Naeije R, Mols P, Hallemans R, Lejeune P, Jaspar N. Pulmonary Vascular Tone Improves Pulmonary Gas Exchange in the Adult Respiratory Distress Syndrome. American Review of Respiratory Diseases. 1987; Volume 136(5): 1232.

8. Ismail N, Bloch KC, McBride JW. Human Ehrlichiosis and Anaplasmosis. Clinical Laboratory Medicine. 2010; 261-292 